DOI: 10.2478/v10122-012-0008-y

\title{
ON THE QUESTION OF TRANSITIVE AND INTRANSITIVE VERBS IN SWAHILI
}

\author{
AGNIESZKA SCHÖNHOF-WILKANS
}

\begin{abstract}
Agnieszka Schönhof-Wilkans. On the Question of Transitive and Intransitive Verbs in Swahili. Lingua Posnaniensis, vol. LIV (1)/2012. The Poznan Society for the Advancement of the Arts and Sciences. PL ISSN 0079-4740, ISBN 978-83-7654-103-7, pp. 89-97.

Swahili does not always make a clear distinction between transitive and intransitive verbs. The question seems to be complicated by the elaborate voice system of this agglutinative language. Subcategories of the Swahili verb such as stative, reciprocal, reflexive, causative, applicative and passive are marked by appropriate affixes. Swahili also applies infixes to signify objects within transitive verbs. Although modern Swahili dictionaries include information about verbal transitivity (TUKI 2001, 2004), it is far from complete. The purpose of this paper is to investigate the problem of transitive and intransitive verbs in Swahili taking into consideration some of the verbal categories, with particular emphasis on the relation of the category of voice to the category of transitivity. The current state of research on the category of transitivity in Swahili will be briefly presented. The material for the analysis has been obtained from various sources, such as Swahili grammars and dictionaries, Tanzanian newspapers and websites, as well as the author's own field notes.
\end{abstract}

Agnieszka Schönhof-Wilkans, Institute of Linguistics, Adam Mickiewicz University, al. Niepodległości 4, PL - 61-874 Poznań

\section{INTRODUCTION}

The category of verb is among the most complex grammatical categories. It embraces words that refer to activities, processes and states of being. One of the most essential functions of verbs is to predicate the subject of a sentence. Verbs can be classified according to their valence, that is the number of arguments that a verb can take. The very notion of valence can be understood twofold: as syntactic and semantic valence. The former refers to "the number of overt morphosyntactically coded arguments" (VAN VAlin \& La Polla 1997: 147), and the latter to "the number of semantic arguments that a particular verb can take" (ibid.). According to their syntactic valence, verbs can be classified into avalent (taking 0 arguments), monovalent or intransitive (taking 1 argument), divalent or transitive (taking 2 arguments), and trivalent or ditransitive (taking 3 arguments). The last are sometimes referred to as complex transitive verbs.

The term transitivity originates in the Latin transire 'to pass, to cross, to go beyond' (trans 'through', ire 'to go'). From the standpoint of Bańczerowski's General Theory of Diathesis, transitivity reflects the property of events in which the sphere of the subject (con- 
ceived of as a syntactic notion) is exceeded, and therefore quantities such as agent, patient or transitificator are included in the event (cf. BAŃCZEROWSKI 2001, 2006).

Normally transitive verbs serve as predicates of transitive constructions. In this respect intransitive verbs should serve as predicates of intransitive constructions. These statements, as trivial as they may seem, can be used as a starting point to address many questions on the nature of transitivity in Swahili - a language that apparently allows transitive constructions to be built on intransitive verbs. Is this really possible; or does there exist some kind of misunderstanding or terminological chaos surrounding the question of transitivity in that language?

The purpose of this paper is to investigate the problem of transitive and intransitive verbs in Swahili taking into consideration some of the verbal categories, with particular emphasis on the relation of the category of voice to the category of transitivity. The current state of research on the category of transitivity in Swahili will be briefly presented. The material for the analysis has been obtained from various sources, such as Swahili grammars and dictionaries, Tanzanian newspapers and websites, as well as the author's own field notes (these being the source where not otherwise stated).

\section{SELECTED ASPECTS OF SWAHILI GRAMMAR}

Swahili is a member of the Bantu language family which is spoken in its dialectal variations by about 80 million people in East, Central and South Africa as well as islands off the coast of East Africa (OHLY et al. 1998: 5). Alongside English, Swahili is an official language in Kenya, Tanzania and Uganda. There are about 5 million native speakers, and for 300,000 of them Swahili is the only language. Swahili is rapidly expanding as a lingua franca in countries of East, Central and South Africa (cf. OhLy et al. 1998, Mulokozi 2003).

The most important morphological features of Swahili include agglutination, the noun class system, a system of agreement (concordance or congruence), elaborate conjugation, as well as the wide use of locative forms (cf. OHLY et al. 1998: 6). Each Swahili noun includes a class prefix attached to the nominal stem denoting singular or plural form, e.g. $m$ - in $m t u$ 'human being' (class 1), wa- in watu 'people' (class 2), ki- in ktabu 'book' (class 7), vi- in vitabu 'books' (class 8). The functions of prefixes are important both morphologically and syntactically. The choice of appropriate forms of adjectives, possessive pronouns, demonstratives, etc. is determined by noun classes, e.g. mtu mzuri 'good man, kitabu kizuri 'good book', watoto wangu 'my children'. Concordance on the syntactic level requires a verb to have a prefix that agrees with the class of the subject and an infix (if present) that agrees with the class of the object, e.g. Mama anawapenda watoto wake wazuri 'Mother loves her nice/beautiful children', where $a$ - 3sg; -na- PRES'; -wa- OBJ 3pl; -penda 'to love'; watoto 'children'; -ake 'his/her'; -zuri 'nice/beautiful'.

Swahili verbal forms are usually very complex in their agglutinative structure. Grammatical relations such as subject, object, tense, mood, and aspect are marked by a system of affixes. In order to emphasise the complexity of this phenomenon some scholars apply the

\footnotetext{
A list of abbreviations is given at the end of the paper.
} 
term 'verbal complex' (cf. OHLY et al. 1998: 57). We shall use the same term in the present article.

The Swahili verbal complex consists of the following items arranged in linear order: subject prefix corresponding to an appropriate nominal class, TAM infix, object infix ${ }^{2}$, verbal root, and verbal extension, which is understood here as a suffix of the category of voice. In cases where different voices are combined together, e.g. causative with passive, a verb includes combined suffixes, sometimes even more than two. The reflexive is marked by the infix $-j i$ - that follows the TAM infix.

Examples:

amekisoma 'he/she has read it (a book)', where $a$ - 1sg; -me- PERF; -ki- OBJ CL7/8; -som- 'to read'; - $a$ ACT. walimpikisha 'they made her/him cook', where wa- 1pl; -li- PAST; -m- OBJ 3sg, -pik- 'to cook', -sha CAUS. wananpendana 'they love each other', where wa-3pl; -na- PRES; -pend- 'to love', - $a$ ACT, -na REC.

anajipenda mwenyewe 'he/she loves himself/herself', where $a$ - 1sg; -na- PRES, -ji- REFL, -pend- 'to love', $-a \mathrm{ACT}$.

nimelazimishwa 'I have been forced', where ni- 1sg; -me- PERF; -lazima- $N$ 'necessity, obligation', -shCAUS, -wa- PASS (-lazimisha 'to force').

The basic word order in Swahili is SVO. Any changes to the word order are attributable to emphasis, definiteness and type of information (i.e. datum vs. novum) (cf. Vitale 1981: 19).

\section{THE CATEGORY OF TRANSITIVITY}

The category of transitivity embraces relations between verbal and nominal phrases in a sentence. It is closely related to the category of case. The following entities (among others) can be distinguished within a sentence: agent (the doer of the action denoted by the predicate), patient (the passive receiver or undergoer of the action), dativus (the active receiver of the action) and stativus (the entity being at a particular state). A transitive verb is a verb that signifies an activity transferring from one entity onto another, the first one being the agent, and the second one being the patient. A further condition is that the agent is an entity not equal to the patient (cf. BAŃCZEROWSKI et al. 1982: 224).

Depending on the adopted criteria, various types of relations will be described as transitive. The same applies when describing verbs of a particular language as transitive or intransitive. For instance in Polish, transitive verbs are those that take a direct object in the accusative for affirmative forms and in the genitive for negative forms of verbs, and sentences with transitive verbs can undergo passive transformation. By contrast, the problem seems to be more complicated in Swahili. Although the terms 'transitive' and 'intransitive' appear in Swahili native grammars in the form elekezi (transitive) and sielekezi (intransitive), and the term 'transitivity' appears as uelekezi or hali elekezi ya vitenzi (cf. KHAMIs 2009, KIHORE 2009), the status of transitivity of some verbs is not clear on the syntactic level. Most definitions of a transitive verb in Swahili restrict themselves to a simple statement like kama kitenzi ni elekezi yaani kinachukua yambwa, au kama kitenzi si elekezi kwa maana kuwa ha-

2 An object infix does not always appear within a verb. In some cases its use is obligatory, whereas in others it is optional. Nevertheless using an object infix may result in a change of meaning of the initial structure. 
kichukui yambwa (CHIDUO 2005: 94) 'when a verb is transitive it takes a (direct) object and when it is intransitive it does not take a (direct) object'. Yambwa (direct object) or yambwa tendewa (HABwE \& KARANJA 2004) is described as mpokea tendo moja kwa moja (KIHORE 2009: 34) 'the direct receiver of the action', whereas yambiwa (indirect object) or yambwa tendwa (HABwE \& KARANJA 2004) has the following definition: mhusika mwingine katika tendo lenye kutolewa na Kiima na kupokewa na Yambwa 'the other participant of the action given away by the subject and received by the direct object'. In most languages sentences with intransitive verbs do not undergo passive transformation, and intransitive verbs alone do not appear in the passive voice; however in Swahili this can sometimes occur. For instance some verbs of motion like -ingia 'enter' do passivize even though they are described as intransitive in TUKI dictionaries.

\section{INSIGHTS FROM PREVIOUS STUDIES ON TRANSITIVITY IN SWAHILI}

The first detailed analysis of the category of transitivity in Swahili was carried out in the 1960s. The major contribution to the study was made by W.H. Whiteley, who published his monograph entitled Some Problems of Transitivity in Swahili (1968). Whiteley was the first to draw attention to the fact that the then existing dictionaries lacked information on two areas in particular - transitivity and verbal extensions. He noticed that although the terms 'transitive' and 'intransitive' appeared in the abbreviations at the beginning of dictionaries, they were not regularly used. Entries including indication of whether or not a Swahili verb can take an object infix would be of great importance to the user (cf. WHITELEY 1968: 3).

In order to provide such information we shall first define 'transitivity/intransitivity' for Swahili; this is a significant task, because most methods developed for Indo-European languages cannot necessarily be applied to a non-Indo-European language. According to some scholars, such criteria as the possibility of taking a direct object or of passivization are not precise enough to be applied to Swahili (cf. Whiteley 1968; OhLy et al. 1998).

Whiteley distinguished five types of sentences including quasi-objects. Sentences differ in their pattern of transitivity, namely the way in which their objects are transformed into the subjects of new sentences (cf. PodoBińska in OHLY et al. 1988: 103): "It is a property of items participating in an object-relationship that they may also participate in a subjectrelationship, and one way of exposing differences in transitivity is to transpose the item(s) in the object-relationship with those in the subject-relationship while retaining the same lexical item" (Whiteley 1968: 10). In order to illustrate the five patterns of transitivity Whiteley gives the following examples:

(o) Mzee yule alikufa njaa. 'That man died of hunger.'

(i) Mtoto huyu anapenda ndizi. 'This child likes bananas.'

(ii) Huyu atafaa kazi. 'He'll do for the job.'

(iii) Mto umeja maji. 'The river is full of water.'

(iv) Mgeni wetu amefika nyumbani. 'Our guest has arrived home.'

In the above sentences the objects have been underlined. Now let us transform the objects into the subjects of new sentences. For (o) such a transformation is impossible. Sen- 
tence (i) is transformed by Whiteley in the following way: Ndizi zinapendwa na mtoto huyu 'The bananas are liked by this child.' There is no object-infix in this case, but the passive marker $-w$ - can be distinguished within the verb as well as the conjunction $n a$ 'by'. Sentence (ii) after transformation reads Kazi itamfaa huyu 'The job will suit him'. An object-infix is obligatory in this case. Sentence (iii) is transformed in the following way: Maji yamejaa mtoni 'Water has filled the river'. There is no object-infix in this case, but there is a locative -ni meaning 'inside'. The last sentence becomes Nyumbani pamefika mgeni wetu 'In the house (there) arrived our guest'. In this case, again, locative markers are used ( $n i$ - and $p a-$ ) and according to Whiteley the sentence suggests "a good reason for not going to the house, as a response to the first speaker's mimi nakwenda nyumbani sasa 'I'm going home now' " (Whiteley 1968: 12-15).

As can be observed, only one of the examples above undergoes classic transformation into the passive. In example (ii) the verb -penda 'like/love' has changed into -pendwa 'be liked/loved' with the suffix of passive voice $-w a$.

In the following examples Whiteley and Mganga (1969: 118) show that the locative class expressed by the use of the suffix -ni (into, inside) influences the semantics of the verb:

Msichana yule alikimbia sokoni 'That girl ran off to the market.'

Msichana yule alikimbia soko 'That girl ran from the market.'

Soko can be subjectivized as follows:

Soko lilikimbia msichana yule 'The market was the scene of the girl's running away.'

One of the major goals of Whiteley's studies was the classification of Swahili verbs by their patterns of transitivity. His research led to the conclusion that many verbs participate in particular patterns, while some participate in several, even all, of these patterns. In their 1969 article Whiteley and Mganga endeavoured to differentiate four groups of verbs, which are shown in the table 1.

Ta b le 1. Whiteley's groups of Swahili verbs classified according to their transitivity pattern (cf. Whiteley \& Mganga 1969: 122)

\begin{tabular}{|c|c|c|c|c|c|c|}
\hline \multirow{2}{*}{\multicolumn{2}{|c|}{ Groups of verbs with examples }} & \multicolumn{5}{|c|}{ Transitivity patterns } \\
\hline & & \multirow[t]{2}{*}{$\mathrm{o}$} & \multirow{2}{*}{$\begin{array}{c}\mathrm{i} \\
\mathrm{X}\end{array}$} & \multirow{2}{*}{$\begin{array}{l}\text { ii } \\
\mathrm{X}\end{array}$} & \multirow{2}{*}{$\frac{\text { iii }}{X}$} & \multirow{2}{*}{$\frac{\text { iv }}{\mathrm{X}}$} \\
\hline I & $\begin{array}{l}\text {-chemk- 'to boil', -bubujik- 'to bubble out', -fura- } \\
\text { 'to swell' }\end{array}$ & & & & & \\
\hline II & $\begin{array}{l}\text {-ingi- 'to enter', -kaz- 'to fix', } \\
\text {-paki- 'to load' }\end{array}$ & & $\mathrm{X}$ & & $X$ & $\mathrm{X}$ \\
\hline III & $\begin{array}{l}\text {-wak- 'to burn', -kauk- 'to dry up', } \\
\text {-tapaka- 'to be scattered' }\end{array}$ & & & $\mathrm{X}$ & $X$ & $\mathrm{X}$ \\
\hline IV & -wak- 'to burn', -zib- 'to be blocked' & $\mathrm{X}$ & $\mathrm{X}$ & & $\mathrm{X}$ & $\mathrm{X}$ \\
\hline
\end{tabular}

Daniel Mkude, in The Passive Construction in Swahili (2005), claims that "Transitivity is usually regarded as a necessary but not sufficient condition for passivization. There are transitive verbs that do not passivize and there are intransitive verbs that can passivize under certain conditions in certain languages" (MKUDE 2005: 17). He also notices that in various languages there exist mechanisms for turning a verb from transitive into intransitive and 
vice versa. In Swahili those mechanisms are predominantly morphological, as we can see in the examples below provided by MKUDE (2005: 17-18)

Mbwa anatembea. 'The dog is walking.' INTR

Joni anamtembeza mbwa. 'John is walking the dog.' TR (-tembeza 'to cause to walk' (-z-CAUS), $-\boldsymbol{m}$ - is the object-infix for $3 \mathrm{sg}$ )

Watoto wanakimbia. 'The children are running.' INTR

Watoto wanamkimbia mbwa. 'The children are running away from the dog.' TR(?) (-m- is the object-infix for $3 \mathrm{sg}$ )

During her fieldwork in Tanzania in 2010, the present author noted the following sentence containing the verb -kimbia 'to run':

Josephat amekimbiwa na mke 'Josephat "has been run away" by his wife' (His wife has left him). The verb -kimbia is marked for passive voice by -w-

In many languages (e.g. Polish) verbs of motion (e.g. 'walk', 'go', 'run', 'enter', etc.) are generally regarded as intransitive. Similarly, the verb 'die' is usually a one-place predicate. Passivization of such verbs in Swahili is not uncommon; however their status of transitivity has not yet been clearly described. Perhaps it is only a question of homonymy in this case. Another hypothesis is that such verbs in Swahili might include incorporated cases. This theory requires a great deal of investigation, as the category of case alone has been treated marginally by scholars of Swahili. The following sentences include the types of verbs mentioned above:

Amefiwa na mume "She has been died by her husband", in which the verb - $f a$ "die' appears together with the passive voice marker $-w$ -

Nimeingiwa na hofu "I have been entered by hope", where the verb -ingia 'enter' is in passive form.

Shule ya huko imeendwa na watoto wazuri 'The school here is attended by good children'.

In this sentence the verb -enda 'go' appears in the passive.

Some scholars (e.g. ABdulaziz 1996) are of the opinion that regarding transitivity as a property of the lexical item is irrelevant. In order to investigate the problem of transitivity as a property of the clause, ABDULAziz (1996) adopted HALlidAY's approach (1967). He discussed transitivity patterns of the Swahili clauses in the framework of four Process Types: Material, Mental, Rational and Verbal. Nevertheless, the scholar seem to notice the importance of the problem of verbal extensions within the category of transitivity: "Confusion is then caused because of the idiosyncratic behaviour of the lexical items to which extensions are added. [...] Identical phonological shapes do not necessarily produce identical process types" (ABDulaziz 1996: 87). Therefore, in Abdulaziz' opinion, Swahili verbal roots and extended forms shall be classified according to their transitivity patterns.

In Amidu's view, transitivity is "simply the ability of a predicate verb to subcategorize or not for object argument MPs [mora phrases], whatever the composition of its inflectional/ derivational morphemes" (AмIDU 2001: 21). The scholar does not insist on direct objecthood as a criterion of transitivity, because in Swahili objecthood is located in a base position both in the macrosyntax and the microsyntax (cf. AmIDU 2001: 21f). Noticing the paradox of the

3 Bolding and additional explanation added by the present author.

4 The sentence means that her husband died and she has been bereaved. 
"transitiveness of 'intransitive verbs' in Kiswahili", Amidu came to conclusion that: "nearly any predicate verb form in Kiswahili Bantu almost always has transitive and intransitive functions, or just a transitive function" (AmIDU 2001: 194).

\section{THE CATEGORY OF VOICE VERSUS TRANSITIVITY}

The category of voice can be understood twofold: as a property of the verb and as an inflection of a sentence (diathesis). In the first case the Swahili verb is inflected to encode voice by the incorporation of appropriate affixes. This does not mean, however, that every Swahili verb is inflected for every voice. For instance intransitive verbs by definition cannot incorporate the passive affix. There are also other constraints on the incorporation of voice affixes, e.g. those of a pragmatic nature when a verb takes several voice affixes at a time (like in wanachekesheana 'they are making themselves laugh' where wa-1pl, -na- PRES, -cheka- 'laugh (STAT)', -sh- CAUS, -ea-APPL, -na REC). In the literature morphological markers of voice in Swahili have been referred to as extended roots, verb(al) extensions, derivational forms, verb forms, etc. Some of these labels, however, seem to be inadequate, for example in case of de-adjectival causative verbs where the so-called base form of the verb does not exist (e.g. -tayarisha 'prepare' originates in the adjective tayari 'ready').

Table 2. The most important Swahili verbal voices and their morphological markers

\begin{tabular}{|c|c|}
\hline Verbal voices & Morphological markers of voice \\
\hline Active (ACT) & $-a,-i,-u,-e^{5}$ \\
\hline Passive (PASS) & -wa, -iwa, -ewa, -liwa, -lewa \\
\hline Stative (STAT) & $-k a,-i k a,-e k a,-l i k a,-l e k a,-u k a$ \\
\hline Applicative (APLL) & $-i a,-e a,-i l i a,-e l e a$ \\
\hline Causative (CAUS) & -isha, -esha, -iza, -eza, -sha, -za, -ya, -sa \\
\hline Reciprocal (REC) & $-n a$ \\
\hline Reflexive (REFL) & $-j i-$ \\
\hline
\end{tabular}

As far as the inflection of verbs for voice is concerned, the following question arises: in what way is the category of voice intertwined with the category of transitivity? Is it possible to clearly state that a given group of verbs of particular voice takes one feature of transitivity or intransitivity? Since, as is generally agreed, transitive verbs take a direct object and sentences with transitive verbs describe events with two different entities (agent and patient), Swahili applicative and causative verbs must be regarded as transitive. What is more, such verbs are usually ditransitive, and sentences based on them are of SVOO type as in WHITELEY's example (1968: 69): Mwenzake alimlimia Ali shamba lake 'His friend cultivated Ali's plot for him'. The predicate includes an object prefix for $3 \mathrm{sg}$. In passive diathesis the sentence reads as follows: Ali alilimiwa shamba lake na mwenzake 'Ali had his field cultivated for him by his friend'. Alilimiwa includes both the applicative marker (- $i-)$ and the passive voice marker $(-w-)$.

A causative verb appears in the following sentence: Juma alimpikisha mke wake ugali 'Juma made his wife cook ugali for him'. Here an object prefix for $3 \mathrm{sg}(-m-)$ is present, and

\footnotetext{
${ }^{5}$ Bantu verbs end with $-a$, while those of Arabic origin end with $-e,-i$, or $-u$.
} 
the sentence can be transformed into the passive as follows: Mke wake alipikishwa ugali na Juma 'His wife was made to cook ugali by Juma'. The sentence *Ugali ulipikishwa mke wake na Juma 'The ugali was caused to be cooked by his wife by Juma' was regarded as unacceptable by native speakers of Swahili.

Causativization and applicativization are mechanisms that increase the valence of a verb by one. As a result of these processes intransitive verbs become transitive and monotransitive verbs become ditransitive. Double causativization, although very rare, is also possible in Swahili, i.e. Juma alimsafishisha mke wake nyumba 'Juma made his wife clean the house' where the causative morpheme -sh- is reduplicated. Theoretically, we can construct a sentence with a transitive predicate undergoing double causativization, e.g. *Amina alimlipishisha Juma watoto pesa 'Amina made Juma give money to the children'. However such constructions tend to be avoided by Swahili speakers, who prefer to use paraphrases with -fanya 'do, make, cause' (cf. Podobińska in OHLy et al. 1998: 109).

In sentences with reciprocal and reflexive verbs the agent and the patient are the same entity. Such sentences cannot be passivized. Hence reciprocal and reflexive verbs must be regarded as intransitive.

Stative verbs are one-place predicates and therefore cannot be passivized. The morpheme $-k$ - is a stative marker in Swahili. Stative constructions are similar to passive constructions in that their subjects are detopicalized. In Bantu studies stative constructions have been referred to as neutral, potential, middle-voice, anticausative or resultative (cf. MKUDE 2005: 142). Stative constructions lack agents:

mti umeanguka 'the tree has fallen',

kikombe kimevunjika 'the cup has broken' (cf. kikombe kimevunjwa na yeye 'the cup has been broken by him/ her' - the passive construction)

\section{CONCLUSIONS}

It was not the purpose of this paper to investigate exhaustively the category of transitivity in Swahili, but to draw attention to the problem of distinguishing transitive and intransitive verbs in the language, especially in the light of the relationship between the category of transitivity and the category of voice. On the example of some previous approaches to the problem (e.g. Whiteley 1968, MKUDE 2005) it was shown that the understanding of verbal transitivity in Swahili is very different than in Indo-European languages. This paper suggests the need for a more thorough research in order to describe adequately the complexity of the category of transitivity in Swahili.

\section{ABBREVIATIONS}

ACT - active; APPL - applicative; CAUS - causative; INTR - intransitive; OBJ - object pronoun; PASS - passive; PAST - past tense; PERF - perfectum; PRES - present tense; REC - reciprocal; REFL - reflexive; STAT - stative; TR - transitive 


\section{REFERENCES}

Abdulazız Mohamed H. 1996. Transitivity in Swahili. East African languages and dialects, Vol. 5. Köln: Rüdiger Köppe Verlag.

Amidu Assibi A. 2001. Argument and Predicate Relations in Kiswahili. A New Analysis of Transitiveness in Bantu. Köln: Rüdiger Köppe Verlag.

Bańczerowski Jerzy. 2001. "Some Aspects of the Category of Diathesis in Korean.” In: Cheong \& PAK 2001: $31-53$

BańcZerowski Jerzy. 2006. “A Contribution to a Theory of Transitivity in Japanese." Scripta Neophilologica Posnaniensia VIII, 3-24.

Bańczerowski Jerzy, Pogonowski Jerzy, ZgóŁKa Tadeusz. 1982. Wstęp do językoznawstwa. Poznań: UAM.

Cheong Byung-Kwon, PAK Cheong-Wu (eds.). 2001. Je 8 hwe jeonggi haksul daehwe. Haksul Daehwe Nonmunjip. Seoul: Hanguk Dong Yureop Balkan Hakhwe, Hanguk Wegugeo Daehakkyo, Dong Yureop Balkan Yeonguso.

Chiduo E.K.F. 2005. "Ulinganishi wa muundo wa vitomeo katika kamusi mbili za Kiswahili - Kiingereza." Kioo cha Lugha 3, 1, 86-100.

Dimitriadis Alexis, Seidl Amanda. 2002. "Statives and Reciprocal Morphology in Swahili." In: SauZet \& ZribiHERTZ 2002.

Dixon Robert M.W., Aikhenvald Alexandra Y. 2000. "Introduction.” In: Dixon Robert M.W., Aikhenvald Alexandra Y. Changing Valency: Case Studies in Transitivity. Cambridge: CUP, 1-29.

Habwe John, Karanja Peter. 2004. Misingi ya Sarufi ya Kiswahili. Nairobi: Phoenix Publishers.

Halliday M.A.K. 1967. "Notes on Transitivity and Theme in English." Part 1. Journal of Linguistics 3, 37-81.

Khamis Aвdu M. 2009. Stadi za Lugha ya Kiswahili. Sarufi 1. Taasisi ya Uchunguzi wa Kiswahili: Chuo Kikuu cha Dar es Salaam.

KIANGo John Gongwe. 2003. "Syntactic Analysis of Swahili Verbal Expressions." Africa \& Asia 3, 64-90.

Kinore Yared M. 2009. Stadi za Lugha ya Kiswahili. Sarufi 2. Taasisi ya Uchunguzi wa Kiswahili: Chuo Kikuu cha Dar es Salaam.

LodHi A.Y. 2002. "Verbal Extensions in Bantu (the case of Swahili and Nyamwezi)." Africa \& Asia 2, 4-26.

Mkude Daniel J. 2005. The Passive Construction in Swahili. Tokyo: Research Institute for Languages and Cultures of Asia and Africa.

MuLокоzi M.M. 2003. "Kiswahili as a National and International Language." Journal of the Institute of Kiswahili Research 66, 68-80.

Ohly Rajmund, Kraska-Szlenk Iwona, Podobińska Zofia. 1998. Język suahili. Warszawa: Dialog.

SAuzet Patrick, Zribi-Hertz Anne. 2002. Typologie des langues d'Afrique et universaux de la grammaire. Paris: L'Harmattan.

TUKI. 2001. Kamusi ya Kiswahili-Kiingereza. Swahili-English Dictionary. Toleo la Kwanza. Taasisi ya Uchunguzi wa Kiswahili (TUKI): Chuo Kikuu cha Dar es Salaam.

TUKI. 2004. Kamusi ya Kiswahili Sanifu. Toleo la Pili. Nairobi: Oxford University Press.

Van Valin Robert D., La Polla Randy J. 1997. Syntax. Structure, Meaning and Function. Cambridge University Press.

Vitale Anthony J. 1981. Swahili Syntax. Publications in language sciences, no. 5. Dordrecht and Cinnaminson, NJ: Foris Publications.

Whiteley W.H. 1968. Some problems of transitivity in Swahili. London: School of Oriental and African Studies.

Whiteley W.H., Mganga J.D. 1969. "Focus and Entailment - Further Problems of Transitivity in Swahili." African Language Review 8, 108-125. 